\title{
"É como se você fosse fazer a coisa artesanalmente": Uma leitura das marcas de distinção no documentário O Renascimento do Parto.
}

\author{
Aline de Andrade Ramos Cavalcanti - \\ Doutoranda da Universidad Autònoma de Barcelona - CAPES - Brasil ${ }^{1}$
}

DOI:http://dx.doi.org/10.5565/rev/periferia.509

\begin{abstract}
Resumo
Uma análise da emergência das categorias de liberdade e não intervenção no parto importadas da economia política para as técnicas corporais de assistência humanizada, nos permitiu identificar e compreender o desenvolvimento de estratégias e táticas na promoção desse modelo: o cinema documentário. $O$ presente artigo argumenta que a obra fílmica $O$ Renascimento do Parto do casal de ativistas Eduardo Chauvet e Érica de Paula ao debater o modelo de assistência ao parto no Brasil e propor mudanças, reforça mecanismos de distinção social por meio de uma série de discursos e classificações que objetivam suas disposições de classe na obra. Ao analisar os argumentos do filme e suas articulações com os conceitos de habitus, gostos e estilos de vida, bem como, as ambiguidades e contradições do conceito de humanização articulado ao ideário neoliberal, busco iluminar algumas questões políticas que estão presentes na construção do discurso e experiência de parto humanizado trazido pela obra.
\end{abstract}

Palavras chaves: Humanização do parto, cinema documentário, Mercado, Distinção.

\begin{abstract}
An analysis of the emergence of the categories of freedom and non-intervention in childbirth imported from political economy to the physical techniques of humanized assistance allowed us to identify and understand the development of strategies and tactics in promoting this model: the documentary film. This article argues that the filmic work The Renaissance of the Childbirth activist couple Eduardo Chauvet and Erica de Paula to discuss the (delivery) model of childbirth care in the Brazil and propose changes to strengthen mechanisms of social distinction through a series of speeches and classifications that aim their class provisions in the work. By analysing the arguments of the film and its links with the concepts of habitus, tastes and lifestyles, as well as the ambiguities and contradictions of the concept of
\end{abstract}

1 Enviar correspondencia a: Aline de Andrade Ramos Cavalcanti

aline.deandrade@yahoo.com.br 
Autor/es, título, perifèriax(y), mes 2016

revistes.uab.cat/periferia

humanization articulated to the neoliberal ideology, seek to illuminate some political issues that are present in the construction of discourse and humanized childbirth experience brought by the work.

Keywords: Humanization of childbirth, Documentary cinema, Market, Distinction.

\section{Introdução}

A relevância da análise do documentário O Renascimento do Parto (2012) do casal de ativistas brasileiros Eduardo Chauvet e Érica de Paula partiu da necessidade de compreender como as categorias de liberdade e não-intervenção importadas da economia política para o discurso e técnicas corporais de assistência ao parto aparecem representadas e radicalizadas na principal estratégia de promoção desse modelo de assistência: o cinema documentário. Observamos que a partir dos anos 2000, a produção de filmes sobre parto, além de tática, cada vez mais tem impactado nas escolhas e vivências das mulheres, bem como, na implementação de políticas públicas visando à humanização da assistência à saúde no Brasil (Cavalcanti 2014; Diniz 2014).

O surgimento de um movimento de mulheres em torno do parto natural é históricamente bem localizado. A literatura sobre humanização do parto relata que a partir da década de 1950 começaram a surgir um número sem fim de associações nos países industrializados com o objetivo de oferecer alternativas ao parto tecnocrático. Inspiradas no livro do obstetra inglês Dick-Read, Childbirth without fear, um grupo de mães e consumidoras tanto no Reino Unido como nos Estados Unidos fundaram a National Childbirth Trust - NTC e a International Childbirth Education Association - ICEA que se tornaram as primeiras organizações formais a impulsionar um movimento e serviços de asistência ao parto natural (Odent 2003:72).

Esses movimentos irão ganhar maior legitimidade quando em 1979 inicia-se no Comitê Regional da Europa, um debate sobre a expansão da tecnologia aplicada ao nascimento, o crescente aumento da taxa de cesarianas e seus custos associados. Tais discussões resultaram numa ampla agenda de pesquisa sobre os serviços perinatais na Europa promovidas pela Organização Mundial de Saúde (OMS) que resultou no relatório histórico Having a baby in Europe publicado em 1985 (British Journal of Obstetrics and Gynaecology 1992). 
Autor/es, título, perifèriax(y), mes 2016

revistes.uab.cat/periferia

O cenário que permitiu o aparecimento do discurso de crítica às intervenções no parto coincide com a entrada do Banco Mundial na disputa pelo controle discursivo das políticas de saúde a nível global. Sua ingerência nesse âmbito iniciou-se por meio da produção de uma série de relatórios a partir de 1975, alguns anos depois,

da criação do Departamento de Projetos Demográficos criado com o objetivo de controlar o nascimento dos pobres (Rizzotto 2000:115). Tais documentos tinham como eixo programático um ataque frontal aos direitos sociais à saúde, sobretudo a sua universalidade, cuja estratégia política implícita, era a de assegurar o pagamento das dívidas dos países periféricos que estavam passando pelos programas de ajustes estruturais. Como resultado, essas recomendações irão se caracterizar num ostensivo projeto de desospitalização, privatização e investigação sobre procedimentos em função dos custos (Correia 2005, 2007; Rizzotto 2000; Mattos 2001; Misoczky 2003).

É possível situar nesse mesmo período, a incorporação das categorias de liberdade e não-intervenção, como discursos orientadores das novas técnicas corporais de assistência ao parto, num documento que se tornará estratégico e norteador do movimento pela humanização a partir dos anos 90: Maternidade segura: Assistência ao parto normal (OMS 1996). Nesse guia, a definição de parto ganha uma metáfora neoliberal ${ }^{2}$ que diz que: No parto normal, deve existir uma razão válida para interferir no processo natural (OMS 1996:10).

Há uma retórica que encontramos nas propostas e estratégias do Banco Mundial que vai aparecer fortemente no discurso de humanização do parto a partir dos anos 2000, o discurso de "satisfação das necessidades básicas" (Rizzotto 2005:122). Nós encontramos este mesmo discurso elaborado teoricamente como uma filosofia/teoria do parto e nascimento na literatura produzida pelo obstetra francês Michel Odent que será um autor central na difusão da "fisiologia do parto". O discurso sobre a fisiologia do parto será repetido, pronunciado, citado, revisitado, reelaborado, incensantemente na mídia, na literatura, em filmes, programas de tv,

2 Observamos na definição de parto normal um sentido para o processo de assistência que equivale a relação estado/economia do ponto de vista neoliberal, onde o estado não deve interferir no âmbito do mercado. 
Autor/es, título, perifèriax(y), mes 2016

revistes.uab.cat/periferia

jornais, matérias, pesquisas e políticas como a mais contundente justificativa/evidência para fundamentar uma prática não-intervencionista na assistência ao parto. Segundo o Odent:

Para parir, uma mulher precisa liberar um certo coquetel de hormônios. Vamos esquecer o nome de todos esses hormônios (ocitocina, endorfinas, prolactina, ACTH, catecolaminas etc.). A questão crucial é perceber que todos

se originam na mesma glândula - o cérebro. Hoje, o entendimento tradicional, que separa o sistema nervoso do endócrino, está obsoleto. Só há uma rede, e o cérebro também é uma glândula endócrina. Mas não é o cérebro todo que é ativo como uma glândula endócrina, só suas partes mais profundas. Podemos dizer que, quando uma mulher está em trabalho de parto, a parte mais ativa de seu corpo é seu cérebro primitivo - aquelas estruturas muito antigas do cérebro (o hipotálamo, a glândula pituitária etc.) - que compartilhamos com todos os outros mamíferos. (Odent 2002a:31).

Para o autor, a ideia de manejo no parto baseia-se "numa falta de entendimento da fisiologia do parto e das necessidades básicas das mulheres em trabalho de parto", pois o conhecimento fisiológico permite entender que as necessidades básicas da mulher que dá à luz é "sentir-se segura, sem se sentir observada" (Odent 2004:126). O tema da segurança e da não observação, na teoria de Odent, trata-se de defender e garantir para as mulheres um ambiente de total privacidade para que elas possam dar à luz de forma fisiológica.

No discurso de Michel Odent, os princípios de liberdade e não-intervenção são radicalizados e intimamente aliados aos princípios de privacidade e autonomia individual da mulher sobre seu parto/corpo que irá agregar ao sentido de responsabilidade individual, o sentido de responsabilidade planetária. Tal justificativa, se assenta na não reprodução do "Homo superpredador", espécie que atualmente domina o planeta e que tem como traço genético, segundo o autor, a "fraca capacidade de amar e o "potencial para agressão, como matar, guerrear e estuprar (Odent 2010:62). Todo este conjunto de ideias faz de Odent um autor chave e que se faz presente nas principais obras fílmicas sobre parto desde os anos 1980 (Cavalcanti 2014). 
Autor/es, título, perifèriax(y), mes 2016

revistes.uab.cat/periferia

A partir de uma extensa revisão da produção de filmes, observamos que em 1990 surge um boom de documentários sobre parto, tanto no Brasil, como na Europa e Estados Unidos. Este acontecimento coincide com a recomendação do Banco Mundial no início da década para que os governos façam investimentos em "Información, educación y comunicaciones, destinadas a crear demanda de serviços clínicos, alertar a las mujeres y a otros acerca de indicios de peligros" (Banco Mundial 1993:116).

Uma marca central da produção de filmes desse período é que se começa a delinear-se as discussões e argumentos que servirão de estratégias pedagógicas para a abertura mais adiante de um mercado de serviços alternativos de assistência ao parto. Uma recorrência comum tanto no Brasil como nas demais obras a nível global é a necessidade de documentar e divulgar pesquisas científicas, sendo no Brasil bastante forte a produção de vídeos institucionais produzidos por órgãos oficiais de governo ${ }^{3}$ (Cavalcanti 2014:81-82).

É no entando, nos anos 2000 que a produção de filmes de parto se consolida como um novo ramo ou gênero de filmes e um aspecto marcante dessa década é a incorporação dos filmes na própria experiência de parto das mulheres. Também observamos o aprofundamento da produção voltada para a indústria de cinema e televisão, desenvolvendo estratégias de exibição e distribuição e ainda, por uma promoção de uma rede de prestadores de serviços, que a partir de então, se evidenciarão cada vez mais como personagens centrais de várias obras ${ }^{4}$ (Cavalcanti 2014:84).

A partir de 2010 a produção de filmes se consolida como tática de difusão do parto humanizado e segue avançando e aprimorando suas estratégias de produção,

3 Como por exemplo os filmes $A$ vida pede passagem e De volta às Raízes (1995) este último da obstetra Esther de Albuquerque Vilela em parceria com Lívia Martins. Ver lista de filmes do período (Cavalcanti 2014:82-84).

$4 \quad$ Como por exemplo o documentário Born to Brazil da cineasta americana Cara Biasucci, filme baseado na dissertação de mestrado de Kristine Hopkins que foi exibido na televisão brasileira e vários festivais de cinema e eventos científicos. E o curta Birth Day antropóloga e parteira mexicana Naoli Vinaver que se consagrou como a parteira mais famosa do mundo. Ver lista de filmes do período (Cavalcanti 2014:88-93). 
Autor/es, título, perifèriax(y), mes 2016

revistes.uab.cat/periferia

circulação e comercialização das obras que a partir de então, contarão com o apoio cada vez mais ostensivo das TICS (crowdfunding, sites, blogs etc.). Um outro aspecto que vale ressaltar é o projeto político destas obras que tem como meta promover discursivamente uma revolução nos sistemas de saúde ${ }^{5}$ tanto no âmbito do Brasil como a nível global. E esta pretensão dos diretores/ativistas se expressam

nas grandes estratégias de circulação e projeção das obras (cinemas de todo o país, em todo um continente e ainda na difusão das obras em diversos países de todos os continentes do mundo $)^{6}$. Nesse sentido, observamos que 0 Renascimento do Parto (2013) se insere como uma obra fundamental para compreender a produção do discurso atual sobre parto humanizado pela estreita articulação que a obra faz entre humanização, mercado, status, distinção e consumo, bem como sua aliança a estas grandes estratégias ativistas de produção cultural.

Entretanto, se faz imprescidível delimitar o conceito de humanização do parto a ser tratado, na medida em que o conceito em suas formulações recentes é permeado por uma intensa disputa de sentidos, o que o torna às vezes impreciso inclusive na definição do Ministério da Saúde, cujas políticas estão orientadas à promoção da humanização (Diniz 2005; Deslandes 2004).

Vale a pena resgatar o debate sobre o conceito entre alguns autores do campo da saúde coletiva, o qual nos permite uma aproximação às possiblidades significantes das práticas. Assim, humanização pode funcionar: como mudanças na cultura hospitalar, com a organização de uma assistência realmente voltada para as necessidades das mulheres e suas famílias (Domingues e Dias 2005:700); como anseio das lutas empreendidas pela população brasileira, movimentos de mulheres e profissionais da saúde que resistem à crescente mercantilização e desumanização da assistência (Barbosa 2006:325); como um projeto existencial de caráter político,

5 Como exemplo o projeto de produção do filme Freedom for Birth de Toni Harman e Alex Wakeford.

$6 \quad$ Freedom for birth (2012) Toni Harman e Alex Wakeford na Inglaterra, Orgasmic Birth (2008) de Debra Pascali-Bonaro nos Estados Unidos e O Renascimento do Parto (2013) de Érica de Paula e Eduardo Chauvet no Brasil são exemplos de obras que se basearam nestas estratégias. Para ver lista de filmes desse período (Cavalcanti 2014:94-102). 
Autor/es, título, perifèriax(y), mes 2016

revistes.uab.cat/periferia

como uma proposta para a polis (Ayres 2005:552); como reconhecimento e produção de redes de trabalho afetivo (Teixeira 2005:593); como experiência concreta de um homem em processo de produção de si e de sua saúde (Benevides e Passos 2005:570); como sistemas médicos de cura que visam preencher as fraturas simbólicas, psíquicas e sociais produzidas pelo sistema médico antropocêntico (Martins 2003:229) entre outros.

No presente artigo, trataremos o conceito de humanização como a legitimidade científica da medicina ou da assistência baseada em evidências (Diniz 2005:633)

por compreender que este se tornou um sentido hegemônico no interior do campo da luta por mudanças na assistência ao parto, tanto no Brasil, como no Mundo. Um tratamento dado ao conceito que se repete constantemente na literatura, assim como no cinema documentário é a associação entre humanização e um tipo de parto: o parto domiciliar. A menção aos países baixos como uma referência em cuidados humanizados, especialmente, o sistema de atenção ao parto na Holanda (classificado como um sistema humanista por seu baixo nível de intervenções, com uma taxa de $30 \%$ de partos domiciliares e um dos índices de mortalidade perinatal mais baixos do mundo) é comumente reverenciado em muitas obras fílmicas pelo respeito à liberdade de escolha das mulheres sobre sua assistência (Patah e Malik 2011:188; Odent 2002b:XXV; Cochrane 2000:68).

Tais associações entre humanização e parto domiciliar no discurso fílmico, abrem uma lacuna para identificar uma série de marcas distintivas que nos permite compreender algumas lógicas sociais, culturais e políticas que vem associadas à promoção desse modelo no argumento desenvolvido pelos diretores da obra. No tópico a seguir, irei pontuar algumas chaves analíticas partindo da contribuição teórica de Bourdieu - A Distinção: crítica social do julgamento - que nos permitirá identificar a partir da análise do discurso fílmico, como o movimento pela humanização do parto ao promover mudanças nas prácticas, colabora também para o aprofundamento de práticas de diferenciação social, sendo este, o objetivo central da presente análise.

\section{Gostos, habitus e estilos de vida}


Autor/es, título, perifèriax(y), mes 2016

revistes.uab.cat/periferia

A reflexão de Bourdieu sobre a formação dos gostos e estilos de vida repousa sobre a análise da formação de uma classe "pequeno burguesa" cujas estratégias e modos de aquisição de cultura e suas definições de gosto refletem os gostos de classes a qual se encontram posicionados no espaço social, cujas escolhas produzem os próprios mecanismos diferenciação, onde o habitus irá funcionar como um princípio gerador de práticas classificáveis, bem como a capacidade (gosto) de diferenciar e apreciar estas práticas e produtos (Bourdieu 2006:162).

Vandenberghe diz que Bourdieu ao resgatar o conceito aristotélico de héxis e construir o conceito de habitus desenvolveu um instrumento de mediação que permite articular as estruturas e as ações dos agentes, resolvendo assim a antinomia entre objetivismo e subjetivismo. Neste sentido, os conceitos de habitus e campo estabelecem uma cumplicidade ontológica ao ponto de cada conceito referir-se a mesma coisa sob perspectivas diferentes:

O habitus é a interiorização ou incorporação de estruturas sociais, enquanto o campo é a exteriorização ou objetivação do habitus [sempre tendo em mente que] o habitus como princípio gerador e de ações, avaliações e percepções [...] também estrutura o mundo social (Vandenbergue 2010:64-66).

Para Bourdieu, a eficácia própria do habitus é bem visível quando as mesmas rendas estão associadas a consumos muito diferentes. Desta forma, as correlações entre renda e consumo, dizem respeito ao fato que o gosto funciona como um produto de uma forma que é possível quase sempre atribuir a renda à eficácia causal que se exerce apenas em associação ao habitus que ela produziu. Ou seja, os princípios das diferenças, que definem "os estilos de vida" residem na variação da distância objetiva e subjetiva ao mundo, as suas restrições materiais e urgências temporais ${ }^{7}$ (Bourdieu 2006:352). Para Bourdieu:

Não basta ter um milhão para ficar em condições de levar a vida de milionário: e os recém-chegados levam, em geral, muito tempo - às vezes, uma vida inteira - para aprender que, em sua nova condição, o que eles 
Autor/es, título, perifèriax(y), mes 2016

revistes.uab.cat/periferia

haviam considerado uma prodigalidade culpada, faz parte das despesas de primeira necessidade. Esquecemos que, por exemplo, para apreciar "no seu devido valor", os serviços totalmente simbólicos que em grande número de itens (hotéis, salões de cabelereiro etc.), fazem o essencial da diferença entre os estabelecimentos de luxo e os estabelecimentos comuns, convém sentir-se o destinatário legítimo desses cuidados e dessas atenções burocraticamente personalizadas e conservar, em relação aqueles que são pagos para oferecer tais serviços, um misto de distância (do qual faz parte a outorga de 'generosas' gratificações) e de liberdade, semelhante àquele que os burgueses mantém com seus servidores (Bourdieu 2006:351).

Assim, para o autor, as práticas de consumo da pequena burguesia representam a boa vontade cultural e da sua pretensão diante da cultura legítima, mediante as quais tende e sente-se autorizada a confundir-se com ela. Por tanto, essa postura irá funcionar como sua principal estratégia, no qual ao oferecer a todos o sentimento de estar à altura do consumo legítimo, reune duas propriedades habitualmente excludentes, ou seja, a acessibilidade imediata do produto oferecido e os sinais exteriores da legitimidade cultural (Bourdieu 2006:303). Por outro lado, as marcas de distinção são ilustradas perfeitamente na classe dominante por quê:

Les dominants n'apparaissent comme distingués que parce que, étant en quelque sorte dans une position positivement distinguée, leur habitus, nature socialement constituée, est immédiatement ajusté aux exigences immanentes du jeu, et qu'ils peuvent ainsi affirmer leur différence sans avoir besoin de le vouloir, c'est-à-dire avec le naturel est la marque de la distinction dite "naturelle" (Chevallier e Chauviré 2010:47)

Nas classes populares, as práticas de consumo, que as destituem dos signos de distinção dizem respeito ao fato destas relações terem como princípio a escolha do necessário, o que faz com que se compreenda que os ajustes as oportunidades objetivas que está inscrito nas disposições constitutivas do habitus encontrem-se na origem de todas as escolhas realistas (Bourdieu 2006:355). Desta forma, o autor avança na crítica ao consumo cultural partindo das disposições das classes 
Autor/es, título, perifèriax(y), mes 2016

revistes.uab.cat/periferia

médias [pequena burguesia] em se distinguir das outras frações de classe a partir de sua introdução na corrida do consumo e da concorrência, [...] pelo fato de que se sente legitimada a ensinar-Ihes o estilo de vida legítimo por uma ação simbólica, cujo efeito consiste apenas em produzir a necessidade de seu próprio produto (Bourdieu 2006:343). Assim, Bourdieu aponta os princípios da dissimulação pequeno-burguesa que se mascaram de novas profissões e de discursos de subversão às hierarquias e ordem natural das coisas como uma estratégia de manipulação e reconversão de suas posições de classe:

É assim que, na luta travada por ela no seio das frações dominantes da classe dominante, para substitutir o conservadorismo primário, baseado em uma representação abertamente autoritária das relações hierárquicas entre classes, gerações ou sexos, por um conservadorismo reconvertido, em conformidade com os interesses bem compreendidos, daqueles que, em uma utilização racional do sistema escolar, descobriram o meio de conseguir a reconversão imposta pela nova lógica da economia, a burguesia nova ou renovada encontra sua aliada natural, tanto no plano econômico quanto no plano político, na nova pequena burguesia que reconhece nela a realização do seu ideal humano [...] e colabora com entusiasmo no empreendimento de imposição de novas normas éticas - particularmente, em matéria de consumo - e das necessidades correspondentes (Bourdieu 2006:344).

Portanto, as marcas de distinção podem ser identificadas a partir dos sistemas de classificação adotados pelas diversas classes, como estratégias de se diferenciar a partir das escolhas realizadas, onde ao se manifestar através de signos, tais objetos nada mais são que as representações de suas posições de classe objetivadas no espaço social. A identificação das propriedades, bens, escolhas que funcionam como signos do "bom gosto", como signos de classe, dissimulam o jogo de relações e disputas que se encontram nesta fração de classe na lutas pela classificação. É nesse sentido que a pequena burguesia ocupará um papel central de sua análise, sobretudo por sua condição de diferenciação em relação as classes populares, bem como sua disputa com as classes dominantes na qual tende a desenvolver uma prática de consumo que afirme suas pretensões de monopólio de classe. A posição 
Autor/es, título, perifèriax(y), mes 2016

revistes.uab.cat/periferia

da pequena burguesia em relação às grandes instituições de produção e circulação cultural, tende a colocá-las, segundo Bourdieu, a uma posição de solidariedade com as classes dominadas, devido a sua instabilidade na estrutura social e a se reconhecer nos discursos que visam a questionar a ordem cultural e as hierarquias que a "hierarquia" cultural visa manter, e, por outro lado, a reencontrar os tópicos de todas as heresias: denúncia da pretensão (tecnocrática) ao monopólio da competência, hostilidade às hierarquias e à hierarquia, ideologia da criatividade universal (Bourdieu 2006:343).

Tais discursos conformam novos jogos de classificação, desclassificação e reclassificação que sob o simulacro de "marginal" e "exclusão", silenciam sob os adjetivos de "inclassificação", a reclassificação destes atores, em uma classe, ocupando novamente novas disposições no espaço social que para o autor:

Apesar de suas práticas falarem de classificação, mas sob o modo de denegação [...] tomadas de empréstimo ao índex de um repertório dos "recursos" da anticultura adolescente: [...] outras tantas palavras e expressões mal disfarçadas por uma espécie de sonho de voo social e por um esforço desesperado para arrancar-se da força de atração do campo social da gravidade (Bourdieu 2006:348).

Para Bourdieu (2006) a contracultura, têm em comum com a cultura legítima o fato de deixar seus princípios de maneira implícita, e neste sentido, por compreender disposições de ethos, está habilitada ainda a executar funções de distinção por colocar, ao alcance de quase todos, os jogos distintivos, as poses distintas e outros sinais exteriores de riqueza interna que, até então, eram reservados aos intelectuais (Bourdieu 2006:349).

Por fim, o conceito de campo é crucial para compreender os espaços onde estas práticas de distinção se realizam, na medida em que é no campo, entendido como uma arena, um espaço de disputa, que as lutas pela concorrência, pela distinção competitiva se dão; sobretudo porque é nestes espaços que os indivíduos procuram manter ou alterar as relações de força e a distribuição das formas de capital a ele específicas (Vandembergue 2010:69). É nesse sentido que o cinema documentário ativista, como uma prática social do campo onde ocorre a luta pela humanização e 
Autor/es, título, perifèriax(y), mes 2016

revistes.uab.cat/periferia

mudanças nas técnicas e práticas de assistência, parece reforçar práticas sociais distintivas e será onde buscaremos identificar as diversas estratégias de reconversão presentes em toda a obra.

\section{Metodologia de análise}

Para cumprir a presente análise utilizamos uma metodologia de pesquisa qualititativa - análise do discurso em filmes - na qual partimos das contribuições metodológicas de Sánchez et al. (2012) e Denzin (2004), para este último:

A metodologia de uma sociologia crítica da interpretação visual é recente. Os sociólogos que analisam representações sociais comumente utilizam-se de fotos, publicidade, gravação audiovisual, textos narrativos, televisão, documentários, filmes e filmes de Hollywood (Denzin 2004:237).

Para desenvolvê-la, realizei em um primeiro momento, uma decomposição do filme por partes de sequências, cenas e falas e num segundo momento analisei o material com base no objetivo e quadro teórico delimitado. Para sistematizar toda a informação coletada também me utilizei de uma ficha analítica para dar conta dos contextos de (A) produção, (B) circulação e (C) consumo da obra ${ }^{8}$ (Sanches et al. 2012:09). Segundo o autor, é interessante investigar as imagens científicas que são representadas no cinema que - para muitas pessoas é uma fonte principal de conhecimento científico - especialmente no momento em que a ciência e tecnologia não são apenas motores de desenvolvimento econômico, mas também, produtores de estilos de vida.

Para escolher a obra brasileira, parti de uma extensa revisão de filmes (Cavalcanti 2014) a qual submeti aos seguintes critérios: 1) Forte argumento em favor da humanização do parto; 2) Ser bastante exibida; 3) Complexidade do debate em torno do tema; 4) Ser produzida por profissionais ativistas pela humanização do parto; e por fim, 5) Estar alinhada ao gênero documentário.

Com base na ficha analítica e nos procedimentos destacados pontuarei os principais elementos da obra (dentro dos limites do presente texto) para me deter em 
Autor/es, título, perifèriax(y), mes 2016

revistes.uab.cat/periferia

seguida numa análise crítica do discurso fílmico que me permita identificar as tácticas distintivas trazidas pelo argumento dos diretores da obra com base na contribuição teórica de Bourdieu.

\section{O Renascimento do parto: contexto de produção, circulação e consumo}

\section{A. Contexto de produção: sinopse e fontes do argumento}

Sinopse:O filme "O Renascimento do Parto" retrata a grave realidade obstétrica mundial e, sobretudo brasileira, que se caracteriza por um número alarmante de cesarianas ou de partos com intervenções traumáticas e desnecessárias, em contraponto com o que é sabido e recomendado hoje pela ciência. Tal situação apresenta sérias conseqüências perinatais, psicológicas, sociais, antropológicas e financeiras. Através dos relatos de alguns dos maiores especialistas na área e das

mais recentes descobertas científicas, questiona-se o modelo obstétrico atual,promove-se uma reflexão acerca do novo paradigma do século XXI e sobre o futuro de uma civilização nascida sem os chamados "hormônios do amor", liberados apenas em condições específicas de trabalho de parto 9 .

Com base na sinopse, no projeto ${ }^{10}$ descrito no site Benfeitoria e no tópico ${ }^{11}$ "a causa" do site oficial da obra, identificamos quatro elementos que nos permitem depreender a fonte dos argumentos em que se baseiam os autores para desenvolver a obra: (1) O debate sobre a alta taxa de cesarianas nos Brasil e as

9 Segundo Odent: Em termos gerais, a existência desses neurormônios complexos confirma nossa crença na interconectividade de todos os aspectos da vida sexual e, uma vez que a secreção balanceada de hormônios é uma questão delicada, altamente influenciável pelas condições externas e estados psicológicos, representa mais um argumento poderoso contra a interferência médica ou a pertubação do processo fisiológico do parto (Odent 2002b:17).

10 o projeto. Disponível em:<http://benfeitoria.com/o-renascimento-doparto>. Acesso em: 03/07/2014.

11 A causa. Disponível em: <http://orenascimentodoparto.com.br/\#/a-causa>. Acesso em: 03/07/2014. 
Autor/es, título, perifèriax(y), mes 2016

revistes.uab.cat/periferia

Recomendações da OMS; (2) A questão da violência obstétrica; (3) A filosofia de Michel Odent sobre a fisiologia do parto e os hormônios do amor e a (4) A Medicina Baseada em Evidências. Para argumentar a relevância do documentário os diretores debatem a situação das taxas de cesariana e do parto normal no país, para realizar uma crítica à cultura tecnocrata e intervencionista da assistência ao parto, que nas palavras dos mesmos, se perpetuam por meio de mitos ${ }^{12}$.

A questão da cesariana enquanto um problema de grande magnitude vivido por usuárias da saúde suplementar é algo que aparece no discurso dos diretores associados a "um sistema médico" o qual chamaram de "questão financeira" que rege o nascimento. Para os diretores as intervenções perigosas e traumáticas estão desalinhadas "com a prática médica corrente ${ }^{13}$ e refletem o desconhecimento das necessidades básicas de uma mulher em trabalho de parto". En resumo, estes são os quatro pilares em torno do quais se organiza o argumento da obra.

\section{B. Personagens e cenas do discurso científico}

Os diretores de $O$ Renascimento do Parto apresentam catorze profissionais como personagens da obra, destes: (2) obstetrizes, (1) ator, (1) antropóloga médica, (1) enfermeira obstetra, (5) médicos obstetras, (1) psicóloga perinatal, (1) nutricionista e mãe, (1) médico pediatra, (1) médica epidemiologista, (1) doula e (3) parteiras tradicionais. Ainda falam no filme: (8) mães (empresária, médica obstetra, servidora pública, dona de casa, professora PhD, contadora, gestora pública e bióloga).

O elenco do filme é basicamente composto por ativistas nacionalmente conhecidos no círculo do movimento pela humanização do parto, alguns deles tiveram e tem forte influência no avanço da implementação de políticas públicas no Brasil como

12 O projeto. Disponível em:<http://benfeitoria.com/o-renascimento-doparto>. Acesso em: 03/07/2014.

13 É interessante observar que para os diretores a Medicina Baseada em Evidências aparece como uma prática já estabelecida, algo que se reflete também em cartazes informativos, nos quais os diretores dispensam quaisquer fontes dos estudos. Em 1996, a Medicina baseada em evidências foi definida como "consciencioso, explícito e judicioso uso das atuais melhores evidências nas tomadas de decisões a respeito do cuidado individual dos pacientes" (Sherbeeny e Ashoush apud Luzes 2007: 457-458). 
Autor/es, título, perifèriax(y), mes 2016

revistes.uab.cat/periferia

por exemplo Daphne Rattner e Melania Amorim; outros na articulação do movimento ativista e oferta de serviços de parto domiciliar como a obstetriz Ana Cristina Duarte e a parteira mexicana Naoli Vinaver e ainda na produção da reflexão sobre o tema como Ricardo Hebert Jones e Laura Uplinger entre outros. Um famoso ator brasileiro e sua esposa - Márcio Garcia e Andrea Santa Rosa - aparecem como personagens estratégicos para o processo de marketing e propaganda do filme.

No site oficial da obra os diretores compartilham um mini currículo de cada especialista que participa da obra e uma marca que se repete na descrição de todos os personagens é seu reconhecimento internacional e nacional na área. Por fim, um aspecto que merece ser comentado e que se repete como uma tendência mundial em muitas obras é a participação do obstetra francês Michel Odent (que tem uma de suas obras homenageada no título do filme) e também da antropóloga norteamericana Robbie Davis-Floyd que junto esse autor se faz presente na maioria da produção fílmica recente sobre parto.

Observa-se que a fala dos personagens tem um forte apelo à pedagogia do parto, bem como, à promoção do mercado de serviços e produtos voltados para a maternidade. Isso se expressa em cenas que retratam grupos de apoio às

gestantes (nos quais as mulheres fazem trabalhos corporais com os bebês), algumas cenas onde as mulheres aparecem utilizando novos produtos de maternidade (carregando seus bebês em slings) e ainda na própria fala das mulheres quando relatam suas experiências, carregadas de informações trazidas pelo discurso da Medicina Baseada em Evidências (MBE) que propõe toda uma nova rede de atores na organização da assistência.

No filme, os diretores elegem uma experiência de violência no parto como privilegiada: A cesariana. É a tragédia da cesariana eletiva vivida por uma classe social específica, de usuárias da saúde suplementar (privada) que é colocada como problema central no debate da narrativa fílmica. Há outro elemento que emerge em diversas cenas que diz respeito a uma forte crítica às instituições e a insatisfação dos profissionais de saúde frente ao pagamento por procedimentos, pois para eles, não compensa financeiramente atender partos nos hospitais. No argumento fílmico parir naturalmente aparece como anti-produtivo e, portanto, um modelo não- 
Autor/es, título, perifèriax(y), mes 2016

revistes.uab.cat/periferia

lucrativo para os hospitais e profissionais ${ }^{14}$ :

Existe alguns planos de saúde que chegam a pagar até $R \$ 180,00$ pro médico fazer um parto. $\mathrm{R} \$ 180,00$ ? É uma responsabilidade muito grande [...] um hospital que não te dá nenhum tipo de suporte, de estrutura física, chega um ponto que você cansa. (Chauvet 2013:23min).

As oito primeiras partes do filme buscam desconstruir ponto a ponto todo 0 imaginário, práticas, técnicas, valores, percepções e ideias sobre os modelos existentes de assistência ao parto, em especial, sobre a cirurgia cesariana. Observa-se que as alternativas ao modelo existente se constroem discursivamente a partir da produção do medo, da sensação de risco e terror, onde um conjunto de enunciados se articulam em inúmeras cenas que por meio de uma farta utilização de recursos fílmicos amplificam a percepção da violência durante os procedimentos. As cenas de cesariana, por exemplo, são representadas com uma sonoplastia de suspense, com cortes bruscos, mais lentos ou em close, provocando mal estar e choque no expectador. O debate sobre a violência no parto na fala das mulheres aparecem alicerçados a uma experiência pessoal ressignificada pela pedagogia do parto que se expressa na serialização de expressões típicas do discurso ativista, um aspecto que demarca olugar dos sujeitos como personagens autorizados para a fala:

São mulheres às vezes que estão na sua primeira gestação e são abatidas numa cesariana sem dor nem piedade (Chauvet 2013:16min, 50seg).

A ressiginificação de sua experiência de parto segundo o olhar da pedagogia médica torna clara ao mesmo tempo a experiência de violência desautorizada na ordem do discurso na medida em que a mulher que não compreender os sentidos e os processos de intervenção no seu corpo, não está apta a proferir um discurso legítimo, informado e competente de mulher que se sentiu violada no seu parto:

A gente não consegue ter o parto de nossas mães, minha mãe teve três partos normais [...] e a gente fica naquela coisa assim, o que é que está acontecendo com o nosso corpo, com a nossa história que a gente não tá 
Autor/es, título, perifèriax(y), mes 2016

revistes.uab.cat/periferia

conseguindo fazer mais o que deveria ser normal, que os outros mamíferos, os outros animais fazem. (Chauvet 2013:11min, 16seg).

As cenas de fala das mulheres ativistas parecem contribuir para a formação de uma subjetividade feminina no parto, na medida em que, a experiência da violência de um grupo social específico (que fala) generaliza mediante seu discurso a percepção da violência, dos desejos, necessidades, gostos, estilo de vida como algo que define a experiência de todas as mulheres. No filme observamos uma verdade de si como experiência autorizada no discurso de humanização. Outro aspecto que emerge no discurso das mulheres, diz respeito à beleza que é evocada como direito na experiência de nascimento, é o direito à beleza o elemento que foi roubado nas experiências de cesariana, pois o acesso à beleza, a poesia do parto são elementos presentes quando as mulheres relatam a vivência do respeito na assistência:

No fim das contas achei muito bonito, tudo muito bonito, eu acho que o parto natural é uma grande poesia, é muito poético quando você realmente deixa o instinto e seu corpo trabalhar (Chauvet 2013:56min,14seg).

O argumento para a adoção do modelo humanizado na obra transcende a lógica da sobrevivência. Não basta a mulher e o bebê sobreviver, a proposta é qualidade, qualidade comoescolha, personalização, artesanato:

A ideia é qualidade, é a delicadeza e em cada parto, em cada aspecto [...] a gente não quer sobrevivente, a gente quer gente bem recebida (Chauvet 2013:50min, 30seg)

É como se você fosse fazer a coisa artesanalmente, você não pega sua mulher e joga, entra naquele esquema de produção em série de parto (Chauvet 2013:50min, 55seg).

Quando o parto é uma opção, os riscos da cesariana e do parto normal hospitalar intervencionado desaparecem, essa é uma ambuiguidade na obra. Por fim, observamos que a retórica da Medicina Baseada em Evidências coloca em cheque suas próprias recomendações. Se as mulheres puderem escolher, "o parto será maravilhoso" e na obra são apresentados dados de que $20 \%$ das mulheres querem 
Autor/es, título, perifèriax(y), mes 2016

revistes.uab.cat/periferia

ter uma cesariana ${ }^{15}$. Perguntamos: O respeito à escolha informada aliada a uma taxa de cesarianas realmente necessárias seriam capazes de atender as recomendações de 15\% da Organização Mundial de Saúde como aceitável? Por fim, este parece ser um discurso científico ambíguo trazido pelo argumento fílmico.

\section{Discussão: uma leitura das marcas de distinção}

Uma das primeiras marcas distintivas que identificamos na obra a partir do contexto de produção se expressa no capital cultural dos diretores - uma doula e um cineasta - o qual torna bastante visível suas disposições de classe, bem como, o papel tático que a obra ocupa nesse contexto de reconversão cultural em capital econômico o qual favorece suas próprias posições de poder no interior do campo. A escolha estratégica pela ferramenta cinematográfica demonstra uma predisposição distintiva, sobretudo, pela atração das pequenas burguesias às artes médias, já bem identificadas por Bourdieu.

A boa vontade cultural dos diretores representada como "afinidades eletivas" na construção de um discurso e imaginário dissidente, parecem dizer muito mais respeito ao seu próprio habitus, ou seja, a incorporação de suas posições de classe no espaço social. As escolhas dos personagens e sua promoção como novos profissionais, como enunciadores do "consenso no dissenso", dissimulam suas

pretensões de reclassificaçãoque se expressam na postura de questionamento as hierarquias e estruturas que formam a "indústria obstétrica hospitalocêntrica". Um aspecto relevante é a representação majoritária de profissionais liberais autônomos, prestadores de serviços de atendimento ao parto, no qual, ao se pronunciarem como experts das questões que envolvem a assistência atual, não fazem mais que promovorem a si mesmos como as próprias soluções através de seus serviços que se encontram, no seus posicionamentos, "na vanguarda da ciência": 
Autor/es, título, perifèriax(y), mes 2016

revistes.uab.cat/periferia

A luta que os cientistas travam no interior do campo é sempre uma luta pelo poder de determinar a definição da ciência mais adequada aos seus interesses específicos, definição que, se aceita como legítima, os levaria a ocupar com legitimidade a posição dominante no campo. E, dado que não há árbitro externo e imparcial, as reivindicações de legitimidade científica-e-política são sempre uma função do poder relativo dos grupos em competição (Vandenbergue 2010:77).

Assim, a caracterização inicial dos personagens e a consequente escolha dos diretores configuram a própria obra como uma instância de consagração, na medida em que os personagens escolhidos encontram nesse espaço a legitimidade para se tornarem "outsiders estabelecidos". Um recurso utilizado pelos diretores que reforça mecanismos de auto-reconhecimento, ficou bastante notório na apresentação dos personagens no site, onde todos aparecem como especialistas reconhecidos internacionalmente, contribuindo assim para a legitimação de suas pretensões de monopólio da prática de assistência legítima ao parto. Segundo Bourdieu:

Mantém uma relação dialética com o desenvolvimento de uma corporação de profissionais capazes de produzir a necessidade de seu próprio produto, ou seja, a oferta de um novo mercado de bens e serviços; aliás eles preparam-se para satisfazer essa clientela (Bourdieu 2006:346).

No argumento dos diretores há uma clara diferenciação sobre os sujeitos autorizados no cenário da assistência, onde profissionais da biomedicina aparecem como os únicos profissionais habilitados. Dessa forma, pode-se dizer que a obra reforça a falta de reconhecimento de 60 mil parteiras tradicionais em atividade no Brasil, enquanto uma categoria de referência no movimento pela humanização, algo já identificado por Tornquist (2007) no contexto de fundação da Rede pela Humanização do Parto e Nascimento (ReHuNa). Em contrapartida, o discurso fílmico apresenta a parteira tradicional como uma personagem inserida num 
Autor/es, título, perifèriax(y), mes 2016

revistes.uab.cat/periferia

paradoxo do modelo de parto domiciliar no Brasil, que reintera a permanência no país de uma medicina de classes ${ }^{16}$.

Outra marca distintiva no filme diz respeito a escolha dos locais de filmagem. A maioria dos personagens falam de lugares íntimos, portando alguns signos pessoais que expressam elegância, sofisticação e requinte, na maneira de vestir e de se expressar. O que os personagens e profissionais vendem além de suas teorias, experiências e práticas no campo do parto são suas pretensões de reconhecimento de sua arte de viver, como legítimas. O filme abusa de cenas que expressam o gosto dos personagens, especialmente na fala das mulheres que reivindicam o belo parto como direito, uma luta que vai além do gosto pelo necesário, que seria a defesa de sobreviver ao parto.

Para finalizar, há mais um elemento no qual essas disposições de classe dos personagens se tornam ainda mais visíveis. Isso diz respeito à classificação dada, na obra, à escolha das mulheres. Observamos uma clara autorização e desautorização na ordem do discurso realizado na escolha das personagens, onde tais estratégias de diferenciação reproduzem as mesmas disposições presentes no interior do campo concreto da luta pela humanizaçao, ou seja, quem fala e participa é: (1) A mulher predominantemente branca; (2) A mulher que faz parte de uma família nuclear; (3) A mulher classe média ou celebridade; (3) A mulher de capital cultural elevado e (4) A mulher que vivenciou o parto humanizado. Tal classificação das mulheres como personagens trazem um modelo implícito de espectador que compartilha dos mesmos habitus, gostos e estilos de vida.

O filme tem inúmeras cenas onde mulheres negras e usuárias do Sistema Único de Saúde (SUS) ${ }^{17}$ aparecem passando por procedimentos ou em atendimento, mas em nenhum momento elas foram convidadas a falar. A única fala de uma mulher negra e dona de casa no filme tem sua ressignificação da experiência construída pelos

16 Ver (Chauvet 2013: 1h, 10min, 58seg; 1h, 12min, 08seg).

17 Sistema Único de Saúde (SUS) é o nome do sistema público de saúde brasileiro. 
Autor/es, título, perifèriax(y), mes 2016

revistes.uab.cat/periferia

autores por meio da trilha sonora (que dá uma sensação de suspense ou de perigo iminente) já que a percepção da violência [da mulher] não teve oportunidade, condições ou autorização para o exercício reflexivo ${ }^{18}$.

\section{Considerações finais}

No presente artigo, procurei identificar a partir do contribuição bourdieusiana algumas marcas distintivas no argumento sobre humanização do parto no filme. A partir de uma leitura crítica do contexto de produção (desde os discursos à escolha das personagens), bem como, da representação das disposições sociais dos diversos personagens na obra, tentei compreender as táticas utilizadas pelos diretores na proposta de debater o modelo de assistência ao parto existente e como essas estratégias discursivas reforçam mecanismos de distinção social.

Estamos conscientes da complexidade do debate trazido pela obra e não é nosso propósito esgotar as possibilidades de análises e interpretações sobre o material, ao contrário, o presente artigo pretende contribuir para um campo de estudos críticos sobre documentários ativistas pela humanização do parto, um campo que está em construção e se apresenta como um universo extremamente rico a se explorar.

A partir de um trabalho de investigação anterior que inspira o presente artigo (Cavalcanti 2014), tentei dar conta e ampliar alguns elementos importantes para compreender o impacto e o potencial que filmes desse gênero têm para influir nas culturas de parto e nascimento e na atuação dos movimentos sociais de mulheres.

Operando com algumas categorias trazidas pelo importante trabalho teórico de Bourdieu, mostrei como o filme sustenta esquemas de diferenciação social que favorecem por um lado, processos de subjetivação entre as mulheres a partir das representações construídas como ideais no filme: parto da celebridade, branca, consumidora informada, mãe maravilhosa, da mulher distinta e, por outro a

18 A bolsa rompeu em casa, mas na hora de eu ter o meu parto, o médico subiu em cima de mim junto com a pediatra pra me ajudar, a pediatra tentando empurrar eu mandava força e outro médico subiu aqui em cima e me cortaram pra mim ter minha filha" (Chauvet 2013:46min, 10seg). 
Autor/es, título, perifèriax(y), mes 2016

revistes.uab.cat/periferia

promoção do avanço de um mercado de produtos e serviços ao parto humanizado no Brasil.

Estes aspectos podem também ser identificados em várias outras obras do mesmo gênero ${ }^{19}$, e nesse sentido, observamos que a emergência de uma produção de filmes acompanha o desenvolvimento tanto de um movimento social, como de um mercado de bens e serviços ao redor do tema.

Por fim, a contribuição teórica de Bourdieu permitiu-nos compreender como para além da defesa de uma mudança nas técnicas corporais de assistência ao parto, podemos observar na construção do argumento da obra a promoção de uma arte de viver burguesa, cercada por uma série de estratégias de reconversão de suas disposições sociais. Tais personagens, que ao pronunciar seus gostos como autênticos e legítimos (no campo da assistência ao parto), nos permite identificar a relação e impacto do habitus como estruturante do campo da luta, bem como, permite uma compreensão mais crítica - entre as mulheres - diante da emergência de novos padrões e normas culturais (internalização do habitus) na assistência ao parto e nascimento.

\section{Bibliografia}

Ayres, J. R. (2005). Hermenêutica e humanização das práticas de saúde. Ciência e Saúde Coletiva,10(3),549-560.

http://dx.doi.org/10.1590/S1413-81232005000300013

Banco Mundial. (1993) Informe sobre el Desarrollo Mundial: Invertir en Salud. Washington: Banco Mundial.

Barbosa, R. H. S. (2006). Humanização da Assistência à saúde das mulheres: Uma abordagem crítica de gênero. In Humanização dos cuidados em Saúde. Conceitos, dilemas e práticas (pp.323-350). Rio de Janeiro: Fiocruz. http://dx.doi.org/10.7476/9788575413296

19 Como Orgasmic Birth, Freedom for Birth, The Face of birth - Where the personal gets political, The Business of Being Born entre outros. 
Autor/es, título, perifèriax(y), mes 2016

revistes.uab.cat/periferia

Benevides, R. \& Passos, E. (2005). A humanização como dimensão pública das políticas de saúde. Ciência e Saúde Coletiva,10(3),561-571. http://dx.doi.org/10.1590/S1413-81232005000300014

Bourdieu, P. (2006). A distinção - crítica social do julgamento.Porto Alegre: Zouk.

British Journal of Obstetrics and Gyneacology (1992). WHO appropriate technology for birth revisited. http://www.weikert.de/alexandra/who3.html [Acessado em: 13-12-2013].

Cavalcanti, A. de A. R. (2014). Liberdade para nascer: uma análise do discurso de humanização no cinema documentário ativista. 174f. Dissertação (Mestrado), Universidade Federal de Pernambuco: Recife.

Chauvet, E. (Diretor). (2013). O Renascimento do parto. [DVD]. Brasil:Chauvet Filmes e Master Brasil.

Chevalier, S. \& Chauviré, C. (2010). Dictionaire Bourdieu.Paris: Elipses.

Cochrane, A. L. (2000). Efectividad y eficiencia: Reflexiones al azar sobre los servicios sanitarios. Barcelona: Asociación Colaboración Cochrane Española (ACCE).

Correia, M. V. C. (2005). Da Crise do Welfare State ao estado máximo para o capital. in O conselho Nacional de Saúde e os Rumos da Política de Saúde Brasileira: mecanismo de controle social frente às condicionalidades dos organismos financeiros internacionais. (pp.76-82). 324f. Tese (Doutorado), Universidade Federal de Pernambuco: Recife.

(2007). A Influência do Banco Mundial na orientação da política de saúde brasilera. In Jornada Internacional de Políticas Públicas. http://www.joinpp.ufma.br/jornadas/joinppIII/html/Trabalhos/EixoTematicoA/7 6827900932 3136cf7b0Maria_valeria.pdf [Acessado em: 12-01-2014].

Denzin, N.K. (2004). Reading Film: Using Films and Videos as Empirical Social Science Material. In: Flick, U.; Kardoff, E. V.; Strike, I. (eds). A companion to qualitative research. (pp.237-242). Lodon: Sage.

Deslandes, S. F. (2004). Análise do discurso oficial sobre a humanização da assistência hospitalar. Ciência e Saúde Coletiva, 9(1),7-14.

http://dx.doi.org/10.1590/S1413-81232004000100002

Dias, M. A. B. \& Domingues, R. M. S. M. (2005). Desafios na implantação de uma política de humanização da assistência hospitalar ao parto. Ciência e Saúde 
Autor/es, título, perifèriax(y), mes 2016

revistes.uab.cat/periferia

Coletiva,10(3),699-705. http://dx.doi.org/10.1590/S1413-81232005000300026

Diniz, S. G. (2005). Humanização da assistência ao parto no Brasil: os muitos sentidos de um movimento. Ciência e Saúde Coletiva,10(3),627-637.

http://dx.doi.org/10.1590/S1413-81232005000300019

. (2014). O Renascimento do parto, e o que o SUS tem a ver com isso.

Interface: Comunicação, saúde e educação,18(48),217-220.

http://dx.doi.org/10.1590/1807-57622013.0910

Grefell, M. (2008). Pierre Bourdieu - Key Concepts. Durhan: Acumen.

Luzes, E. M. (2007). A necessidade do ensino da ciência do início da vida. 1538 f.

Tese (Doutorado), Universidade Federal do Rio de Janeiro: Rio de Janeiro.

Martins, P. H. (2003). Contra a desumanização da medicina: crítica sociológica das práticas médicas modernas. Petrópolis: Vozes.

Mattos, R. A. de. (2001). As agências internacionais e as políticas de saúde nos anos 90: um panorama geral da oferta de idéias. Ciência e Saúde Coletiva, 6(2),377-389.

http://dx.doi.org/10.1590/S1413-81232001000200008

Mizoczky, M. C. A. (2003). O Banco Mundial e a reconfiguração do campo das agências internacionais de saúde: Uma análise multiparadigmática. Rap Rio de Janeiro,37(1), 75-97.

Odent, M. (2002a). A Cientificação do Amor.Florianópolis: Editora Saint Germain. . (2002b). O Renascimento do Parto. Florianópolis: Editora Saint Germain. . (2003). O Camponês e a Parteira. Rio de Janeiro: Editora Ground Ltda. . (2004). A Cesariana. Florianópolis: Editora Saint Germain. . (2010). A primeira verdade inconveniente. Revista Tempus Actas Saúde Coletiva, 62-66.

OMS - Organização Mundial de Saúde. (1996). Assistência ao parto normal: um guia prático. Brasília: OPAS.

Patah, L. E. M. \& Malik, A. M. (2011). Modelos de assistência ao parto e taxas de cesáreas em diferentes países. Revista de saúde pública, 45(1), 185-194. http://dx.doi.org/10.1590/S0034-89102011000100021

Rizzotto, M. L. F. (2000). A trajetória da saúde no interior do Banco Mundial. In O Banco Mundial e as políticas de saúde nos anos 90: um projeto de desmonte do 
Autor/es, título, perifèriax(y), mes 2016

revistes.uab.cat/periferia

SUS. (pp. 115-125). 266f. Tese (Doutorado), Universidade Estadual de Campinas: Campinas.

Sánchez, A., Ortuño, P., Romera, C. (2012). Los sentidos de la ciência en el cine. Metodología para su análisis. Razón y palabra, 78,1-23.

Teixeira, R. R. (2005). Humanização e atenção primária a saúde. Ciência e Saúde Coletiva, 10(3), 585-597.

http://dx.doi.org/10.1590/S1413-81232005000300016

Tornquist, C. S. (2007). O Parto Humanizado e a REHUNA. In Seminário Nacional Movimentos Sociais, Participação e Democracia,2, Universidade Federal de Santa Catarina: Florianópolis. Anais.

Wandenbergh, F. (2010). Teoria social realista. Rio de Janeiro: Editora do IUPERJ. http://dx.doi.org/10.5380/rcc.v1i1.40284 